\title{
Live trachoma vaccine and topical therapy
}

\author{
J. GRAHAM SGOTT AND J. E. KERRIGH* \\ University of the Witwatersrand, South Africa
}

It was stated (Scott, 1964) that a live trachoma vaccine had no clear-cut effect in cases of severe trachoma although there were encouraging results in patients with mild trachoma and in a volunteer. This paper, which describes a further study supported by statistical analysis carried out on 553 children over a period of 5 years, confirms that no clear-cut benefit was obtained from the use of a live trachoma vaccine in cases of severe trachoma.

\section{Material and methods}

A school for 300 native Bantu children aged from 7 to 15 years was selected in the Northern Transvaal where classical trachoma was known to be common. Attendance at school was not compulsory and only 193 were present at the first examination in 1965 by Scott and Pienaar, who reached agreement on their findings, each using a loupe in daylight. Pannus of 2 to $3 \mathrm{~mm}$. and Herbert's pits were found in 48 of the first fifty children examined, after which these signs were ignored. The upper lid was everted and three abnormal signs were commonly found.:

(1) Follicles

(2) Hyperaemia

(3) Hyperplasia of the tarsal conjunctiva.

These were not necessarily regarded as signs of trachoma but each was given a figure to represent severity as described later by the statistician. Of the 193 children, I 13 had signs of active infection, nineteen had scars in a quiet eye, and $4^{\mathrm{I}}$ had a normal tarsal conjunctiva.

In the following 3 years, the new intakes of 111,126 and 123 children were examined and the old cases re-examined by the same two ophthalmologists. Swabs for TRIC culture were positive in 91 of 98 unselected children in 1965 ; this high proportion of positives fell to 55,28 , and 8 per cent. in the three successive intakes although the incidence of trachoma and the average point score were much the same in each group. Cultures were done by Mrs. Cuthbertson and Miss Ryan at the South African Institute for Medical Research.

Another curious feature was that a higher proportion of positive cultures came from those with lower total scores (e.g. 3, 2, or I). In each intake there were one or two carriers, i.e. patients with a normal tarsal conjunctiva who yielded TRIc agent on culture but had a total score of 0 .

A live trachoma vaccine (E.I.D. $10^{-3}$ ), prepared at the South African Institute for Medical Research under the direction of Prof. J. H. S. Gear, was given by subcutaneous injection to onethird of the children selected by random numbers. Each vaccinated child was given a second dose a month later and a booster dose each subsequent year. If a patient was absent when the vaccinations took place, every effort was made to give the vaccine at the earliest opportunity and nearly all of the selected children received their quota of vaccine. There was only one case of reaction (allergic oedema). As practically every child in that area contracted trachoma by the age of I year it was decided to treat all scholars (irrespective of initial score) with I per cent. tetracycline ointment once daily during their first school year in the hope that the vaccine would prevent reinfection when treatment was stopped.

A total of 552 children was examined and 184 were given vaccine. An analysis of the results is given below. The response to therapy will be the subject of another communication. 


\section{Statistical report on the findings}

There are two basic groups of patients: those who received the vaccine and those who did not.

Each child was examined from time to time and the severity of each of three signs was noted on a four-point scale: $0,1,2,3$. The sum of these three scores, which can vary from o to 9, is taken as an overall indication of the severity of the disease at a given time. Two typical results are shown in Table I. If observations are missing, it was not possible to find the child on a given date for re-examination.

Table I Results in two patients, one with vaccine and one without

\begin{tabular}{|c|c|c|c|c|c|c|c|c|c|c|c|}
\hline \multirow{3}{*}{ Vaccine } & \multirow{3}{*}{ Patient } & \multirow{3}{*}{ no. } & \multicolumn{9}{|c|}{ Date examined and total score } \\
\hline & & & \multicolumn{3}{|c|}{1965} & \multicolumn{2}{|c|}{ I966 } & \multirow{2}{*}{$\frac{1967}{F e b .}$} & \multirow{2}{*}{$\frac{1968}{F e b .}$} & \multicolumn{2}{|c|}{1969} \\
\hline & & & Feb. & Fun. & Oct. & Jan. & Sept. & & & Feb. & Sept. \\
\hline $\begin{array}{l}\text { Given } \\
\text { Not given }\end{array}$ & $\begin{array}{l}68 \\
6 I\end{array}$ & & $\begin{array}{l}3 \\
3\end{array}$ & $\begin{array}{l}\mathbf{I} \\
\mathbf{O}\end{array}$ & $\begin{array}{l}4 \\
2\end{array}$ & $\begin{array}{l}3 \\
3\end{array}$ & $\begin{array}{l}\text { o } \\
-\end{array}$ & $\begin{array}{l}2 \\
3\end{array}$ & $\begin{array}{l}2 \\
\text { I }\end{array}$ & - & I \\
\hline
\end{tabular}

Each of the two basic groups was divided into subgroups, according to their initial total score (o or I ... or 9) and the date when this was obtained. For each subgroup the average score at each date of re-examination was computed.

A typical result (for initial score 3 and initial date Feb., 1965) is given in Table II and the Figure, for those who received the vaccine and those who did not.

Table II Average scores with and without vaccine

\begin{tabular}{|c|c|c|c|c|c|c|c|c|c|}
\hline \multirow{2}{*}{ Date examined } & \multicolumn{3}{|c|}{ I965 } & \multicolumn{2}{|l|}{ I 966} & \multirow{2}{*}{$\frac{1967}{\text { Feb. }}$} & \multirow{2}{*}{$\frac{1968}{F e h .}$} & \multicolumn{2}{|l|}{ I 969} \\
\hline & Feb. & Fun. & Oct. & Jan. & Sept. & & & $F e b$ & Sept. \\
\hline $\begin{array}{l}\bar{x}: \text { wITH vaccine } \\
\text { No. examined } \\
\text { S.D. of } \bar{x}\end{array}$ & $\begin{array}{r}3 \\
10\end{array}$ & $\begin{array}{l}1 \cdot 22 \\
9 \\
0 \cdot 22\end{array}$ & $\begin{array}{l}2 \cdot 00 \\
9 \\
0 \cdot 60\end{array}$ & $\begin{array}{l}1 \cdot 44 \\
9 \\
0 \cdot 111\end{array}$ & $\begin{array}{l}0 \cdot 55 \\
9 \\
0 \cdot 34\end{array}$ & $\begin{array}{l}2 \cdot 50 \\
8 \\
0 \cdot 94\end{array}$ & $\begin{array}{l}\mathbf{I} \cdot 43 \\
7 \\
0 \cdot 39\end{array}$ & $\begin{array}{l}\text { I } \cdot 00 \\
\text { I } \\
?\end{array}$ & $\begin{array}{l}1 \cdot 50 \\
4 \\
0 \cdot 57\end{array}$ \\
\hline $\begin{array}{l}\bar{y}: \text { wITHout vaccine } \\
\text { No. examined } \\
\text { S.D. of } \bar{y}\end{array}$ & $\begin{array}{r}3 \\
12\end{array}$ & $\begin{array}{l}0 \cdot 86 \\
7 \\
0 \cdot 55\end{array}$ & $\begin{array}{l}2 \cdot 28 \\
7 \\
0 \cdot 66\end{array}$ & $\begin{array}{l}2 \cdot 22 \\
9 \\
0 \cdot 81\end{array}$ & $\begin{array}{l}0 \cdot 43 \\
7 \\
0 \cdot 14\end{array}$ & $\begin{array}{l}1 \cdot 44 \\
9 \\
0 \cdot 29\end{array}$ & $\begin{array}{l}1 \cdot 16 \\
6 \\
0 \cdot 39\end{array}$ & $\begin{array}{l}2 \cdot 00 \\
\mathrm{I} \\
?\end{array}$ & $\begin{array}{l}2 \cdot 20 \\
5 \\
1 \cdot 06\end{array}$ \\
\hline $\begin{array}{l}\bar{x}-\bar{y} \\
\text { S.D. of } \bar{x}-\bar{y}\end{array}$ & 0 & $\begin{array}{r}+\cdot 36 \\
0 \cdot 60\end{array}$ & $\begin{array}{r}-\cdot 28 \\
0 \cdot 89\end{array}$ & $\begin{array}{r}-\cdot 78 \\
0 \cdot 81\end{array}$ & $\begin{array}{l}+\cdot 12 \\
0.38\end{array}$ & $\begin{array}{c}+1.06 \\
0.98\end{array}$ & $\begin{array}{l}+.27 \\
0.56\end{array}$ & $?^{-1 \cdot 0}$ & $\begin{array}{r}-\cdot 70 \\
1 \cdot 2\end{array}$ \\
\hline
\end{tabular}

These two subgroups are logically comparable. When comparing them, either from the table or from the graphs, one would like to see that the mean scores for those vaccinated are smaller than the scores for those not vaccinated, and to see these differences steadily increase as time goes on. This would be evidence that the vaccine helps. But the differences vary in an erratic manner. Furthermore, the estimated standard deviations of the individual differences are so large that no sound statistical evidence exists for judging whether or not any particular "true" difference is positive or negative. 
Many such comparable pairs of subgroups exist and their mean scores were tabulated and graphed. In all cases the two graphs intertwined erratically in much the same way as in the Figure.

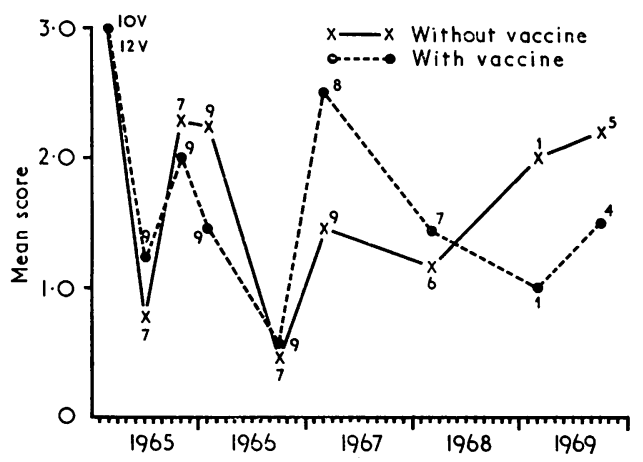

Figure Typical result. See Table II

The disadvantage of having so many comparable pairs of subgroups is that the number of observations in each is small. But any method that can be evolved for combining these subgroups into two large subgroups and comparing them, with the idea of using a statistically more powerful test of the effects of vaccination, necessitates making various assumptions before the comparison can be regarded as valid. These assumptions we are not prepared to make.

In conclusion, then, with the evidence arranged in Tables such as Table II, our judgement is that the vaccine did not help the patients at all.

Clinical and laboratcry studies were supported by a grant from the South African National Council for the Blind. Grateful thanks are expressed to the Council and to the two technicians Mrs. Cuthbertson and Miss Ryan.

\section{Reference}

scotт, J. G. (1964) Trans. ophthal. Soc. U.K., 84, 6 I 5 
prosthetics. The registration fee, which includes luncheons, reception, and the congress banquet at the Royal College of Surgeons, will be:

Members of the European and American Contact Lens Society: $\quad £_{12} \quad$ (\$30)

Non-members: $\quad £ 20 \quad(\$ 50)$

Ophthalmologists in training: $\quad$ f.10 (\$25)

(Non-medical personnel may apply if sponsored by an ophthalmologist).

Application should be made to the Congress Secretary, Moorfields Eye Hospital, High Holborn, London, W.C.r., England.

\section{International Symposium on Geriatric Ophthalmology}

Saint Vincent (Valle d'Aosta), Italy, May zo to June I, I97I

This international symposium will be held under the patronage of the Società Oftalmologica Italiana. Many authoritative speakers have announced their desire to participate and they will be dealing with the physiopathological and clinical aspects of the senile eye.

Those interested should write to the Secretary: Dott. B. Bellan, Ospedale Oftalmico di Torino, Via Juvarra I9- IOI22 Torino, Italy.

\section{Jerusalem Seminar on the Prevention of Blindness August 25-27, I97I}

A seminar on the prevention of blindness will be held in Jerusalem from August 25 to 27, 1971, under the auspices of the Israel Academy of Science and the Humanities. The meeting will discuss measures used for the prevention of blindness in developing and developed countries. More particularly, an attempt will be made to assess the comparative effectiveness and cost of these measures.

The following subjects have been chosen for discussion: keratomalacia, amblyopia, glaucoma, diabetic retinopathy, retinal detachment, cataract, and corneal opacification. The last two subjects will be discussed with special reference to developing countries, and will include trachoma, onchocerciasis, malnutrition, virus diseases, and village medicine.

Those interested should write to Prof. I. C. Michaelson, Hadassah University Hospital, P.O. Box 499, Jerusalem, Israel.

\section{International Society of Geographical Ophthalmology}

\section{Conference, Jerusalem, August 23 and 24, I97 I}

Immediately preceding the above seminar, on August 23 and 24, the second Conference of the International Society of Geographical Ophthalmology will take place. Various aspects of ophthalmic diseases as they appear in various parts of the world will be discussed. Particular reference will be made to the conditions and their incidence which are to be considered in the seminar dealing with the prevention of blindness.

Those interested should write to Dr. E. Cass, Box 24, Fort Smith, N.W.T. I5, Canada.

\section{Corrigenda}

In the paper by J. Graham Scott and J. E. Kerrich entitled "Live trachoma vaccine and topical therapy", which appeared in the March issue (Brit. F. Ophthal. (1971), 55, 189), please make the following corrections:

p. 189 , 1. 1 7 , for 113 read 133

1. 2 from bottom, for 552 read 553

1). I9o, 1. I2, for Table II read Table I

p. $191,1.3$, add: In the Figure, the digits beside each point denote the numbers of observations.

It is regretted that the authors' proof corrections were delayed by the Post Office strike. 